\title{
Pengenalan Retina Menggunakan Alihragam Gelombang Singkat dengan Pengukuran Jarak Euclidean Ternormalisasi
}

\author{
Aris Wijayanti $\mathrm{a}^{\mathrm{*}}$, Suryono ${ }^{\mathrm{b}}$ \\ ${ }^{a}$ Universitas PGRI Ronggolawe, Tuban \\ ${ }^{\mathrm{b} J u r u s a n}$ Fisika Fakultas Sains dan Matematika Universitas Diponegoro
}

Naskah Diterima : 13 April 2014; Diterima Publikasi : 22 Mei 2014

\begin{abstract}
Identification of a retinal biometric identification methods with low error rate due to the unique patterns in the retina of blood vessels behind the retina. These patterns can be used as training data for the recognition system is then used for comparison when the identification is done. This study aims to identify the image of the human eye retina, either the left or right side, using image processing techniques and measuring the normalized Euclidean distance. So far, research on biometric systems, particularly with the object of the eye's retina, the eye is done at the owner from the owner's eyes with diverse backgrounds, such as the Messidor database. In this study created a system that can recognize the retinal image using the transformation Haar short waves by measuring the normalized Euclidean distance. Retinal image will be the initial pretreatment process of changing the original image into a gray image, which is then performed using the Haar wavelet feature extraction to obtain the energy that will be used for the normalization of the Euclidean distance, so that the process of recognition by Euclidean values are compared. Testing is done using eye retinal image database taken from Messidor many as 100 of the 300 images taken at random were then stored in a database, the database is one of 100 images stored, the database of 100 images stored 2, and 3 as many as 100 images database stored. Of the best database testing should be done as much as 6 levels of decomposition levels. From the test results have identified the recognition accuracy rate of up to $98 \%$. The greatest degree of familiarity is level 1 that is equal to $98 \%$. Followed usage by $80 \%$ level 2, level 3 is $59 \%$, level 4 is $47 \%$, level 5 is $45 \%$ and the lowest is the last level 6 that is equal to $37 \%$.
\end{abstract}

Keywords: Retinal image; Database; Euclidean normalized; Haar Wavelet

\begin{abstract}
Abstrak
Identifikasi retina merupakan metode identifikasi biometric dengan tingkat kesalahan rendah karena pola-pola unik pembuluh darah retina di bagian belakang retina. Pola- pola ini dapat digunakan sebagai data latih sistem pengenalan untuk kemudian digunakan sebagai pembanding pada saat identifikasi dilakukan. Penelitian ini bertujuan untuk mengenali citra retina mata manusia, baik bagian kiri maupun bagian kanan, menggunakan teknik pengolahan citra dan pengukuran jarak Euclidean Ternormalisasi. Selama ini, penelitian mengenai sistem biometrik, khususnya dengan objek retina mata, dilakukan pada pemilik mata yang berasal dari pemilik mata dengan beragam latar belakang, seperti pada basis data Messidor. Pada penelitian ini di buat sistem yang dapat mengenali citra retina menggunakan alihragam gelombang singkat Haar dengan pengukuran jarak Euclidean ternormalisasi. Citra retina akan dilakukan proses prapengolahan awal dari mengubah citra asli menjadi citra keabuan, yang kemudian dilakukan ekstraksi ciri menggunakan wavelet Haar untuk mendapatkan energi yang akan digunakan untuk normalisasi jarak Euclidean, sehingga pada proses pengenalan melalui nilai Euclidean yang dibandingkan. Pengujian dilakukan menggunakan citra retina mata yang diambil dari basisdata Messidor sebanyak 100 dari 300 citra yang diambil secara acak yang kemudian disimpan dalam basisdata, yakni basisdata 1 sebanyak 100 citra tersimpan, basisdata 2 sebanyak 100 citra tersimpan, dan basisdata 3 sebanyak 100 citra yang tersimpan. Dari basisdata terbaik harus dilakukan pengujian aras dekomposisi sebanyak 6 aras. Dari hasil uji coba hasil identifikasi memiliki tingkat akurasi pengenalan hingga $98 \%$. Yang paling besar tingkat pengenalannya adalah aras 1 yaitu sebesar $98 \%$. Disusul pemakaian aras 2 sebesar $80 \%$, aras 3 sebesar $59 \%$, aras 4 sebesar $47 \%$, aras 5 sebesar $45 \%$ dan terakhir yang paling rendah adalah aras 6 yaitu sebesar $37 \%$.
\end{abstract}

Kata Kunci : Citra retina; Basisdata; Euclidean ternormalisasi; Wavelet Haar

\section{Pendahuluan}

Karakter manusia yang unik yang digunakan sebagai pengenalan atau identifikasi terhadap seseorang. Hal ini dikenal sebagai pengenalan biometrik. Sistem biometrik misalnya sidik jari, suara, iris, retina, tanda tangan, dan geometri tangan sangat bermanfaat untuk mengenali identitas manusia (Musa et al., 2012). Mengenali identitas manusia ada berbagai cara, diantaranya dapat mengenalinya dari KTP (Kartu Tanda Penduduk), SIM (Surat Izin Mengemudi) dan Paspor. Selama ini pengenalan

*) Penulis korespondensi: ariswjy@yahoo.com 
biometrik menggunakan sidik jari, tanda tangan, wajah, suara menunjukkan tingkat pengenalan yang rendah. Oleh sebab itu perlu dibuat penelitian tentang pengenalan retina yang merupakan metode otomatis yang memberikan identifikasi asli dari seseorang dengan mengambil gambaran retina. Sistem pembacaan retina telah banyak digunakan pada pengimplementasian kontrol akses keamanan tinggi seperti bidang militer, institusi keuangan, bahkan keamanan penjara. Retina memiliki pembuluh yang sifatnya unik yang unik sehingga dapat digunakan untuk identifikasi karena memiliki tingkat penolakan kesalahan yang rendah, hampir nol persen karena pola-pola aliran darah pada retina.

Retina mempunyai bintik kuning (makula lutea). Elemen peka cahaya mengandung sel-sel batang dan kerucut (Moreno et al., 2009). Ada 2 studi terkenal yang menunjukkan keunikan pola pembuluh darah retina (retinal) yaitu:

1. Dr. Carleton Sinton dan Dr. Isodore Goldstein pada tahun 1935 yang menyatakan bahwa retina memiliki pola pembuluh darah yang unik dan berbeda untuk setiap orang. Publikasi mereka selanjutnya menyarankan foto pembuluh darah tersebut untuk pengenalan manusia (Putra, 2009).

2. Dr. Paul Tower pada tahun 1950 mengemukakan bahwa pada pembuluh darah retina adalah berbeda pada setiap orang, bahkan untuk kembar identik (Putra, 2009).

Alihragam wavelet Haar sebagai salah satu metode untuk menganalisis tekstur yang digunakan sebagai pengekstraksi ciri pola retina mata. Pada penelitian sebelumnya telah banyak dilakukan pengenalan menggunakan wavelet Haar tetapi pada iris mata dengan menggunakan data yang sudah tersimpan yang memiliki tingkat pengenalan tertinggi pada aras 4 sebesar 81,20\% (Prihartono, 2011). Dalam penelitian ini, dibuat sebuah pengenalan pada retina menggunakan wavelet Haar dengan data yang sudah tersimpan. Untuk algoritma yang digunakan dalam penelitian ini menggunakan perhitungan dengan mencari jarak dan energi pada citra yang tersimpan. Dari hasil perhitungan jarak dan energi maka didapatkan nilai jarak Euclidean sebanyak N data.

\section{KerangkaTeori}

\subsection{Retina Mata}

Retina adalah selapis tipis sel yang terletak pada bagian belakang bola mata vertebrata dan sefalopoda. Retina merupakan bagian mata yang mengubah cahaya menjadi sinyal saraf. Struktur retina manusia adalah $72 \%$ seperti bola dengan diameter sekitar 22 mm. Pada bagian tengah retina terdapat cakram optik, yang dikenal sebagai "titik buta" (blind spot) karena tidak adanya fotoreseptor di daerah itu. Cakram optik terlihat sebagai area oval berwarna putih berukuran $3 \mathrm{~mm}^{2}$. Gambar 2.1 adalah anatomi mata yang menunjukkan letak retina mata berada.

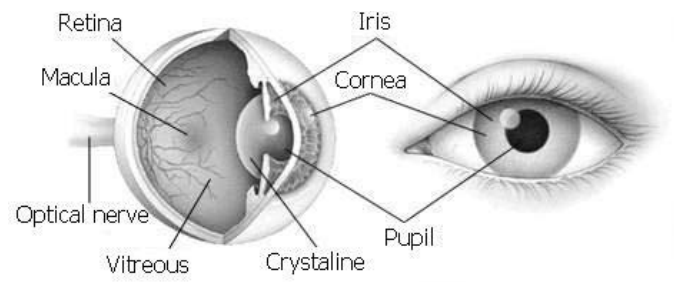

Gambar 1. Anatomi mata (Moreno et al., 2009)

\subsection{Alihragam Wavelet}

Wavelet merupakan sebuah basis. Basis wavelet berasal dari sebuah fungsi penskalaan atau dikatakan juga sebuah fungsi penskala. Fungsi penskala memiliki sifat yaitu dapat disusun dari sejumlah salinan yang telah didilasikan, ditranslasikan dan diskalakan. Fungsi ini diturunkan dari persamaan dilatasi, yang dianggap sebagai dasar dari teori wavelet. Persamaan dilatasi adalah:

$$
\phi(x)=\sum c_{k} \phi(2 x-k)
$$

dari persamaan fungsi penskala ini dapat dibentuk persamaan wavelet yang pertama (atau disebut juga wavelet induk), dengan bentuk :

$$
\psi^{0}(x)=\sum_{k}(-1)^{k} c_{1-k} \phi(2 x-k)
$$

Dari wavelet induk ini kemudian dapat dibentuk wavelet-wavelet berikutnya ( $\psi^{1}, \psi^{2}$ dan seterusnya) dengan cara mendilasikan (memampatkan atau meregangkan) dan menggeser wavelet induk (Prihartono et al., 2011).

\subsection{Wavelet Haar}

Jenis wavelet yang digunakan pada penelitian ini adalah wavelet Haar. Haar adalah wavelet paling tua dan paling sederhana, diperkenalkan oleh Alfred Haar pada tahun 1909. Haar telah menjadi sumber ide bagi munculnya keluarga wavelet lainnya seperti Daubechies dan lain sebagainya.

\subsection{Dekomposisi Citra}

Skema alihragam wavelet 2D aras 1 untuk suatu citra dapat dilihat pada contoh dekomposisi perataan dan pengurangan yang ditunjukan pada Gambar 2 . Alihragam wavelet 2D untuk aras 2,3, dan seterusnya, dilakukan dengan cara yang sama, hanya dilakukan pada bagian LL. Gambar 2 menunjukan contoh alihragam wavelet 2D pada citra retina mata untuk aras 1 . 

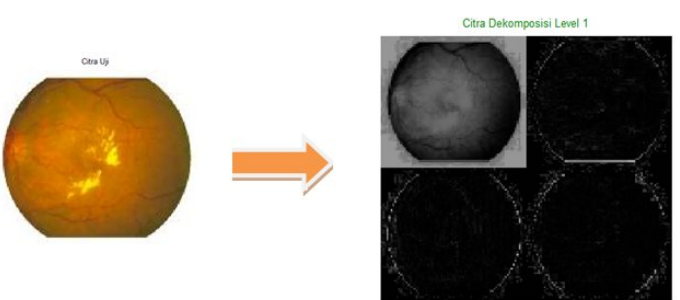

Gambar 2. Gambar dekomposisi wavelet 2D aras 1

\subsection{Pengukuran Energi pada Wavelet}

Perhitungan energi berfungsi untuk menghitung energi yang dihasilkan setiap citra hasil alihragam wavelet. Energi tersebut merupakan koefisien masukan perhitungan jarak Euclidean. Dalam penelitian ini, energi dibagi dalam 4 (empat) ciri, yaitu:

a. Prosentase energi yang berhubungan dengan nilai pendekatan (aproksimasi), $E_{a}$ dihitung berdasarkan prosentase jumlahan kuadrat dari nilai koefisien aproksimasi $C_{a}$ dibagi dengan jumlahan seluruh koefisien $C$ (koefisien aproksimasi ditambah koefisien detail, yaitu $\mathrm{cA}+\mathrm{cH}+\mathrm{cV}+\mathrm{cD})$.

$$
E_{a}=\frac{\sum C_{a}^{2}}{\sum C^{2}} \times 100 \%
$$

b. Prosentase energi yang berhubungan dengan nilai detail pada arah horisontal, $E_{h}$ dihitung berdasarkan prosentase jumlahan kuadrat dari nilai koefisien detail pada arah horisontal $C_{h}$ dibagi dengan jumlahan seluruh koefisien $C$.

$$
E_{h}=\frac{\sum C_{h}^{2}}{\sum c^{2}} \times 100 \%
$$

c. Prosentase energi yang berhubungan dengan nilai detail pada arah vertikal, $E_{v}$ dihitung berdasarkan prosentase jumlahan kuadrat dari nilai koefisien detail pada arah horisontal $C_{v}$ dibagi dengan jumlahan seluruh koefisien $C$.

$$
E_{v}=\frac{\sum C_{v}^{2}}{\sum C^{2}} \times 100 \%
$$

d. Prosentase energi yang berhubungan dengan nilai detail pada arah diagonal, $E_{d}$ dihitung berdasarkan prosentase jumlahan kuadrat dari nilai koefisien detail pada arah diagonal $C_{d}$ dibagi dengan jumlahan seluruh koefisien $C$.

$$
E_{d}=\frac{\sum C_{d}^{2}}{\sum c^{2}} \times 100 \%
$$

\subsection{Jarak Euclidean Ternormalisasi (Normalized Euclidean Distance)}

Euclidean distance atau jarak Euclidean adalah metrika yang paling sering digunakan untuk menghitung kesamaan 2 vektor. Jarak Euclidean menghitung akar dari kuadrat perbedaan 2 vektor. Nilai vektor ciri suatu citra masukan yang memiliki nilai vektor ciri yang sama dengan vektor ciri citra setelah pengolahan akan memiliki nilai jarak Euclidean yang mendekati nol (Hartanto, 2012). Misal nilai vektor ciri masukan citra $A=\left(A_{1}, A_{2}, \ldots . ., A_{n}\right)$ nilai vektor ciri citra setelah pengolahan adalah $B=\left(\mathrm{B}_{1}, \mathrm{~B}_{2}, \ldots, \mathrm{B}_{\mathrm{n}}\right)$, jarak Euclidean antara nilai vektor ciri citra masukan dan nilai vektor ciri citra setelah pengolahan dinyatakan oleh:

$$
D(A, B)=\sqrt{\sum_{i=0}^{n} \frac{\left(\left|A_{i}-B_{i}\right|\right)^{2}}{A_{i}}}
$$

dengan: $D(A, B)$ Jarak Euclidean antara gambar $A$ dan $B$

$A=$ Vektor ciri citra masukan

$B=$ Vektor ciri citra hasil pengolahan

$n=$ panjang vektor (jumlah ciri tekstural) vektor $A$ dan vektor $B$

\section{Metodologi}

\subsection{Desain sistem}

Penggunaan diagram alir juga bertujuan agar suatu rancangan dapat diimplementasikan secara tepat dan terarah. Dalam perangkat lunak pengenalan citra retina menggunakan alihragam wavelet Haar, terdapat proses-proses yang dilakukan dari awal data dipilih, hingga pada akhirnya data tersebut dikenali.secara garis besar, proses-proses tersebut dikelompokkan pada beberapa proses utama yaitu :

1) Memilih citra masukan yang berupa citra digital.

2) Melakukan proses awal berupa pengambilan citra retina.

3) Memasukan citra retina kedalam program utama.

4) Menentukan nilai koefisien dan dekomposisi.

5) Melakukan proses dekomposisi dengan menggunakan alihragam wavelet Haar

6) Melakukan proses perbandingan dengan menggunakan perhitungan jarak Euclidean.

Secara umum diagram alir untuk sistem pengenalan retina yang dirancang dapat ditunjukkan pada Gambar 3 sebagai berikut : 


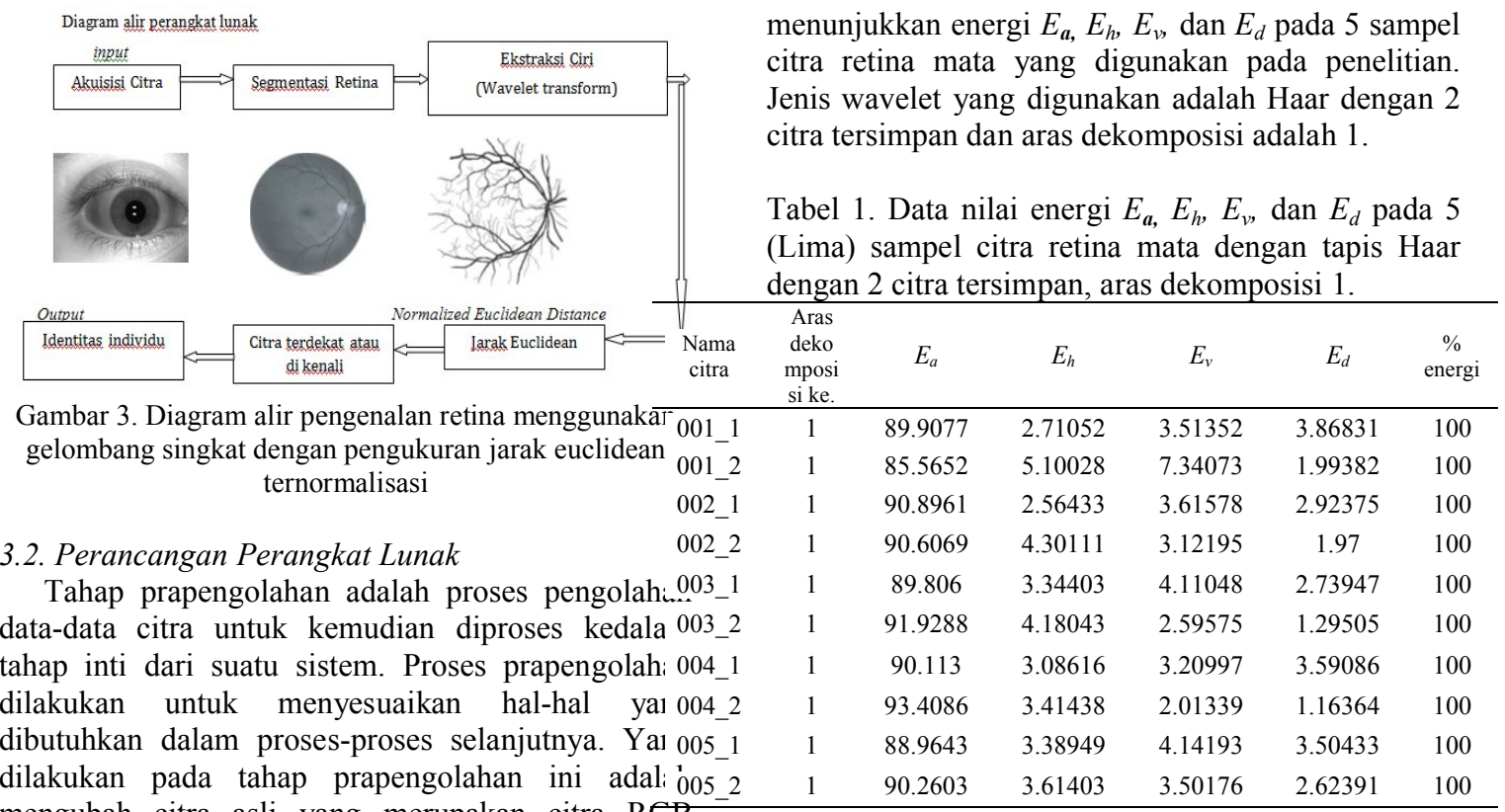
mengubah citra asli yang merupakan citra RGB menjadi citra dengan aras keabuan.

Data citra retina yang digunakan adalah citra dari basisdata Messidor dengan ukuran sebenarnya 700x605 piksel yang kemudian diubah ukurannya menjadi 260x300 piksel, dengan tujuan agar proses pelatihan tidak memakan waktu yang lama dan RAM yang digunakan pada perangkat komputer tidak membutuhkan banyak kapasitas. Pemilihan resolusi ini diajurkan untuk menggunakan perangkat komputer dengan kapasitas RAM yang memadai.

Sebelum dapat digunakan dalam proses $\mathrm{Nam}^{2}$ dekomposisi, citra harus diubah dahulu kedalam citra bentuk aras keabuan. Dalam perancangan perangkat 005 lunak disini, citra yang belum dalam keadaan aras ${ }_{1 . j p g}^{005}$ keabuan akan langsung diubah dalam format aras $005_{-}$ keabuan

Untuk mendapatkan nilai citra yang lebih efisien digunakan koefisien, yaitu menggunakan besarnya nilai ambang yang diberikan. Tetapi sebelum itu dilakukan, dilakukan proses dekomposisi terlebih dahulu. Dalam prosedur kompresi berisi tiga langkah:

1. Dekomposisi

2. Detil koefisien thresholding (ambang dipilih). Untuk setiap level dari 1 sampai $\mathrm{N}$

3. Transformasi balik citra.

Ekstraksi ciri bertujuan untuk mendapatkan informasi penting dari tekstur retina mata. Teknik ekstraksi ciri ini menggunakan fungsi Wavelet Haar yang digunakan untuk mengekstraksi ciri dari citra yang ternormalisasi.

\section{Hasil dan Pembahasan}

\subsection{Pengujian Ekstraksi Ciri}

Pengujian ini menggunakan parameter ars dekomposisi alihragam wavelet Haar. Tabel 4.1
4.2. Pengujian Pengenalan dengan Jarak Euclidean

Dalam pengujian pengenalan jarak Euclidean, digunakan retina mata uji 005.jpg terhadap 2 retina mata yang terdapat dalam basis data, yaitu retina mata 005_1.jpg dan 005_2.jpg.

Tabel 2. Data nilai energi $E_{a}, E_{h}, E_{v}$, dan $E_{d}$ pada 2 sampel citra retina mata dengan wavelet Haar, aras dekomposisi 1 (data uji_1)

\begin{tabular}{cccccc}
$\begin{array}{c}\text { Aras } \\
\text { dekom } \\
\text { posisi } \\
\text { ke.. }\end{array}$ & $E_{a}$ & $E_{h}$ & $E_{v}$ & $E_{d}$ & $\begin{array}{c}\text { Prosent } \\
\text { ase } \\
\text { energi }\end{array}$ \\
1 & 88.9643 & $\begin{array}{c}3.3894 \\
9\end{array}$ & $\begin{array}{c}4.1419 \\
3\end{array}$ & $\begin{array}{c}3.5043 \\
3\end{array}$ & 100 \\
1 & 90.2603 & $\begin{array}{c}3.6140 \\
3\end{array}$ & $\begin{array}{c}3.5017 \\
6\end{array}$ & $\begin{array}{c}2.6239 \\
1\end{array}$ & 100 \\
& & & & & \\
& & & & & \\
\hline
\end{tabular}

Berdasarkan Tabel 2 dan rumus jarak Euclidean ternormalisasi pada bab 2, maka perhitungan jarak Euclidean retina mata adalah sebagai berikut.

Misal $A=005 \_1 . j p g$ (citra uji)

$\mathrm{B}=005 . \overline{j p g}$ (citra dalam basis data) $\mathrm{D}(A, B)$

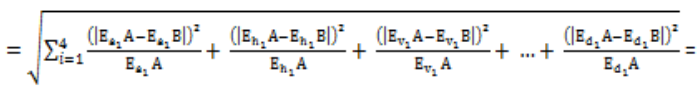

$\sqrt{\sum_{i=1}^{4} \frac{(|88.9643-90.2603|)^{2}}{88.9643}+\frac{(|3.38949-3.61403|)^{2}}{3.38949}+\frac{(|4.14193-3.50176|)^{2}}{4.14193}+\frac{(|3.50433-2.62391|)^{2}}{3.50433}}$

$=\sqrt{0,3538876}$

$=0,59488$

Dengan demikian jarak Euclidean terdekat terhadap retina mata 005 _.jpg, sehingga retina mata 005_2.jpg dikenali benar sebagai retina mata 005.jpg dengan jarak Euclidean 0,59488. 


\subsection{Pengujian Proses Pengenalan}

Dalam pengujian proses pengenalan dilakukan dengan tujuan untuk mengetahui hasil pengenalan terbaik dari variasi aras dekomposisi. Pada pengujian proses pengenalan ini dilakukan pengujian aras dari aras dekomposisi 1 sampai dengan aras 6 menggunakan basisdata yang tersimpan. Berikut adalah 10 (sepuluh) hasil data dari pengujian proses pengenalan.

Tabel 3. Hasil pengujian dengan parameter alihragam wavelet Haar basis data 1 aras 2

\begin{tabular}{cccc} 
Citra Uji & $\begin{array}{c}\text { Dikenali } \\
\text { sebagai }\end{array}$ & $\begin{array}{c}\text { Jarak } \\
\text { Euclidean }\end{array}$ & Keterangan \\
\hline 001_1.jpg & 001 & 0,9760 & Benar \\
002_1.jpg & 002 & 0,7601 & Benar \\
003_1.jpg & 060 & 1,2645 & Salah \\
004_1.jpg & 004 & 1,0915 & Benar \\
005_1.jpg & 005 & 1,3638 & Benar \\
006_1.jpg & 006 & 0,6806 & Benar \\
007_1.jpg & 007 & 1,0128 & Benar \\
008_1.jpg & 008 & 0,6331 & Benar \\
009_1.jpg & 009 & 1,0179 & Benar \\
010_1.jpg & 008 & 0,8360 & Salah \\
\hline
\end{tabular}

Dari pengujian pengujian proses pengenalan pada aras $1,2,3,4,5$, dan 6 dengan menggunakan basisdata (jumlah sampel tersimpan) didapatkan paling besar tingkat pengenalannya adalah aras 1 yaitu sebesar $98 \%$. Disusul pemakaian aras 2 sebesar $80 \%$, aras 3 sebesar $59 \%$, aras 4 sebesar $47 \%$, aras 5 sebesar $45 \%$ dan terakhir yang paling rendah adalah aras 6 yaitu sebesar $37 \%$.

\section{Kesimpulan}

Berdasarkan hasil penelitian tersebut dapat diambil beberapa kesimpulan antara lain :

1. Dari penelitian sistem pengenalan retina didasarkan pada banyaknya jumlah sampel citra yang tersimpan sangat mempengaruhi tingkat pengenalan, semakin banyak data yang tersimpan maka pengenalannya akan cenderung semakin tinggi.

1. Penggunaan aras yang berbeda-beda sangat mempengaruhi tingkat pengenalan, hal ini disebabkan pengeruh energi yang tersimpan pada tingkatan aras yang berbeda akan memiliki energi yang berbeda.

2. Pada pengujian aras $1,2,3,4,5,6$ dengan menggunakan basisdata (jumlah sampel tersimpan) terbaik yakni basisdata alihragam wavelet Haar memiliki tingkat pengenalan masing-masing adalah basis data 1 aras 1 sebesar
$98 \%$ dan basis data 1 aras 2 sebesar $80 \%$, basis data 1 aras 3 sebesar $59 \%$, basis data 2 aras 4 sebesar $47 \%$, basis data 2 aras 5 sebesar $45 \%$, dan tingkat basis data 3 aras 6 sebesar 37\%. Tingkat pengenalan tertinggi adalah pada aras 1 , dan pengenalan terendah adalah pada aras 6 .

3. Perlu dilakukan pengujian dengan data latih yang memiliki tingkat pencahayaan yang sama tiap citranya (standar), yang berarti setiap citra yang dilatih dan diujikan memiliki tingkat pencahayaan yang sama agar pada saat prapengolahan didapatkan aras keabuan yang tepat.

4. Perlu dilakukan ekstraksi ciri dengan menggunakan metode lain untuk mengetahui perbandingan hasil dari wavelet Haar.

5. Perlu dilakukan pengujian menggunakan variasi jumlah lapisan tersembunyi (jamak atau lebih dari satu) untuk mengetahui pengaruh jumlah lapisan tersembunyi dengan tingkat keberhasilan.

\section{Daftar Pustaka}

Hartanto, A,D., 2010. Pengenalan citra iris mata menggunakan alihragam wavelet daubechies orde 4, Transmisi, 12 vol 4, Hal. 145 - 149.

Isnanto, R, Santoso, R., Prihartono, I., Widodo, T,D., Suhardjo, T,S., Susanto, A., 2012. Sistem pengenalan iris mata berdasar tekstur menggunakan ekstraksi ciri energi pada alihragam wavelet haar. Jurnal Sistem Komputer, vol 2 no. 1, Hal. 29 - 34.

Kadir, A. dan Susanto, A., 2013. Teori dan Aplikasi Pengolahan Citra, edisi 1, Penerbit Andi Yogyakarta.

MESSIDOR Database, Retina Image Database, http://www.researchgate.net/post/Retinal_image database 3.

Moreno, R.P. and Gonzaga, A., 2009. Features Vector For Personal Identification Based On Iris Texture, Departamento de Engenharia Elétrica EESC - USP, Hal. 110 - 116.

Musa, P., Nuryuliani., Lamsani, M., 2012. Rancang Bangun pengendali pintu otomatis berdasarkan ciri wajah menggunakan metode euclidean distance dan Fuzzy C-Mean, Hal. 321 - 326.

Purnomo, M.H. dan Muntasa, A., 2010. Konsep Pengolahan Citra Digital dan Ekstraksi Ciri, Penerbit Graha Ilmu, Yogyakarta.

Prihartono, T.D., Isnanto, R.R. dan Santoso, I., 2011. Identifikasi iris mata menggunakan alihragam wavelet. Transmisi, Vol. 13 no. 2, Hal. $71-75$.

Putra, D., 2009. Sistem Biometrika, edisi 1, Penerbit Andi, Yogyakarta. 